Editorial

\title{
New and Renewed Manufacturing Paradigms for Sustainable Production
}

\author{
Daryl John Powell ${ }^{1,2, *(\mathbb{D})}$, David Romero ${ }^{3}$ and Paolo Gaiardelli ${ }^{4}$ (D) \\ 1 Department of Product and Production Development, SINTEF Manufacturing AS, 2830 Raufoss, Norway \\ 2 Department of Industrial Economics and Technology Management, Norwegian University of Science and \\ Technology, 7491 Trondheim, Norway \\ 3 Advanced Manufacturing Research Group, Center for Innovation in Design and Technology, Tecnológico de \\ Monterrey, Monterrey 64849, Mexico; david.romero.diaz@gmail.com \\ 4 Department of Management, Information and Production Engineering, University of Bergamo, \\ 24129 Bergamo, Italy; paolo.gaiardelli@unibg.it \\ * Correspondence: daryl.powell@sintef.no
}

Citation: Powell, D.J.; Romero, D.; Gaiardelli, P. New and Renewed Manufacturing Paradigms for Sustainable Production. Sustainability 2022, 14, 1279. https://doi.org/ $10.3390 /$ su14031279

Received: 17 January 2022 Accepted: 20 January 2022 Published: 24 January 2022

Publisher's Note: MDPI stays neutral with regard to jurisdictional claims in published maps and institutional affiliations.

Copyright: (c) 2022 by the authors Licensee MDPI, Basel, Switzerland. This article is an open access article distributed under the terms and conditions of the Creative Commons Attribution (CC BY) license (https:// creativecommons.org/licenses/by/ $4.0 /)$.

\section{Introduction}

Despite the difficulties created by the COVID-19 pandemic, the year 2020 ushered in a decade of ambitious actions aiming to deliver on the promises made in the United Nations Sustainable Development Goals by 2030. Unfortunately, though progress is being made in many places, such actions are not advancing at the speed and scale required. At the same time, optimism concerning the potential of new manufacturing paradigms such as "Digital Manufacturing" and "Smart Manufacturing" continues to grow-primarily in terms of the economic bottom line, but also with an increasing focus on both the environmental and social bottom lines, such as in the case of the "Circular Manufacturing" paradigm. The promise of digital connectivity, big data analytics, blockchain, cyber-physical systems, and the industrial Internet of Things in these areas remains significant and creates the need for more specific examples of how new and renewed manufacturing paradigms can indeed contribute towards achieving a more sustainable future, particularly with regards to more sustainable production and consumption patterns. As such, in this Special Issue, we present scientific contributions addressing this challenge from various perspectives, providing innovative answers to this multidimensional problem.

\section{New and Renewed Manufacturing Paradigms for Sustainable Production}

In this section, the Guest Editors provide a short overview of the new and renewed manufacturing paradigms and technologies that have contributed to the development of (smart and) sustainable production systems over the decades and discuss their interrelations.

\subsection{Manufacturing Paradigms towards Sustainable Production}

The "Lean Manufacturing" paradigm stems from the work of Taichi Ohno and the Toyota Production System (TPS) [1] and was popularized by [2] in the early 1990s. The intended outcome of this paradigm is a reduction in production costs, the improvement of product and process quality, and the shortening of product delivery times, all while utilizing fewer resources. This manufacturing paradigm focuses on the identification and elimination of waste within a firm's production system through the continuous improvement of products and processes. By comparison, the "Green Manufacturing" paradigm also arose in the early 1990s, this time as a result of the 1992 Earth Summit in Rio de Janeiro, Brazil, where government representatives called on manufacturers to review their environmental impacts and seek ways to reduce or eliminate them through pollution control and prevention as well as product stewardship strategies. This second paradigm concentrates on the renewal of industrial production processes and the establishment of environmentally 
friendly operations and products [3]. Thus, manufacturers have simultaneously adopted these twin paradigms [4] over the last few decades to create an economic and environmental stance that is driven by the minimization or elimination of waste and the reduction in or prevention of pollution to air, water, and land to achieve the development of eco-efficient production systems [5], where it is possible to increase productivity while simultaneously improving environmental performance.

Nevertheless, achieving eco-efficiency has proven to be insufficient to protect people and the planet, as well as the prosperity of businesses, as manufacturers are starting to face the challenge of the rapid depletion of finite production resources, giving rise to the need for a new manufacturing paradigm referred to as "Circular Manufacturing". This concept started to gain popularity in the 2010s, and its popularity continues today. This more recent paradigm is characterized by not only a reduction in the use of (virgin) materials and (nonrenewable sources of) energy in the manufacturing of products but also by the recovery of as much of these as possible at the end of their life cycle for reuse and recycling, leading to the creation of closed-loop production systems [6]. These closed-loop systems focus on taking back products from customers and recovering added value by reusing the entire product and/or some of its modules, components, or parts to obtain increased environmental and economic performance (e.g., remanufacturing) [7].

Moreover, while there is no doubt that the "Circular Manufacturing" paradigm represents a great step forward towards achieving sustainable production systems [8], it does not explicitly refer to the social bottom line of manufacturing, which brings us to the "Sustainable Manufacturing" paradigm. This triple bottom line paradigm involves the creation of production systems capable of manufacturing products through economically-sound processes that minimize negative environmental impacts while conserving energy and natural resources and enhancing employee, community, and product safety [9].

Though much remains to be done in order to achieve truly sustainable production systems, the aforementioned new and renewed manufacturing paradigms represent the efforts of the academic and industrial communities towards creating sustainable production systems.

\subsection{Technology-Based Manufacturing Paradigms Supporting Sustainable Production}

With the arrival of the Fourth Industrial Revolution (or Industry 4.0) in the early 2010s, manufacturers have seen a rapid (digital) transformation of their production systems accompanied by the adoption of advanced design, engineering, and manufacturing technologies and the pursuit of new environmental sustainability efforts [10]. In this technology-enabled industrial transformation trend, two technology-based manufacturing paradigms should be highlighted in support of the development of smart and sustainable production systems: The "Digital Manufacturing" paradigm, which aims to support the carrying out of tasks and decision making based on digital models and simulations in virtual environments without the use of physical prototypes and experiments [11], and the "Smart Manufacturing" paradigm, which focuses on developing cyber-physical production systems (composed of connected human resources and production equipment) that continuously perform real-time analysis and respond to stochastic changes in the system status and its environment, as well as to forecasted events, optimizing themselves according to desired manufacturing goals [12].

Both of these technology-intensive paradigms offer relevant triple bottom line-related benefits leading towards the development of smart and sustainable production systems $[10,13]$ in terms of (a) economic gains, which are enabled by savings through more accurate and precise smart production planning, control, scheduling, and reprogramming systems and shorter lead times thanks to the development of "Digital Lean Manufacturing" [14] capabilities based on agile and flexible cyber-physical production systems designed for rapidly producing a wide variety of high-quality products in small batches at similar costs of those in mass-production to meet customers' demands; (b) environmental gains, which are enabled by increased material, energy, and water efficiency in smart and sustainable manufacturing operations based on the real-time monitoring of production assets' material, 
energy, and water consumption (for example, avoiding manufacturing waste by employing technology-enabled and enhanced 'zero waste' manufacturing approaches [15] to reduce both the consumption of production resources and emissions, as well as adopting 'zero defect' manufacturing approaches [16] to ensure both product and process quality by reducing or eliminating defects through compensation and/or prevention strategies); and (c) social gains, which are enabled by smart wearable and collaborative technologies that increase the productivity, safety, health, and welfare of the workforce [17].

Since achieving sustainability is a balancing act of the triple bottom line, digital and smart manufacturing technologies offer great opportunities for the development of smart and sustainable production systems since these two technology-based manufacturing paradigms provide the ability to simulate and model beforehand in order to evaluate, optimize, and achieve sustainable materials, energy, water usage, and workforce efforts in production processes and monitor the resource consumption of production in real-time for additional optimization to achieve next-level environmental, economic, and social performance [18].

\section{Contributions to Sustainable Production Development}

This section provides a summary of the nine papers that are included in this Special Issue following a rigorous peer-review process and their respective contributions to the field of sustainable production.

Firstly, Lu [19] develops a fuzzy network data envelopment analysis for the selection of alternative Advanced Manufacturing Technologies (AMTs) considering multiple decisionmakers and weight restrictions when input and output data are represented as fuzzy numbers. The author suggests that since the adoption of AMTs can offer significant sustainability and efficiency improvements in manufacturing, this approach provides a practical decision aid for selecting relevant AMTs; this will help companies to realize new manufacturing paradigms of sustainable manufacturing.

Córdova-Aguirre and Ramón-Jerónimo [20] explore the incorporation of sustainability into strategy and management control systems in Peruvian manufacturing enterprises in the plastics sector. By focusing on identifying and analyzing the current way in which sustainability is incorporated and managed, the authors determine the shortcomings that must be corrected in the future in order to design an effective performance management system that includes the concept of sustainability to help companies achieve sustainable growth.

Subramaniam et al. [21] investigate both the positive and negative impacts of COVID19 on digital transformation. Their research shows that the positive elements far outweigh the negatives, with the results of the study clearly highlighting that the disruption caused by the pandemic is leading to technology adoption and disruption in the form of automation and collaboration-specifically through allowing "working from anywhere", which otherwise removes geographical barriers and office dependency.

Pfeifer [22] investigates the application of a Smart Manufacturing Execution System (SMES) in a Small and Medium-sized Enterprise (SME) in the Czech Republic and proposes a smart manufacturing architecture for SMEs. Though the system appears suitable for simple, standardizable work tasks, the research uncovers the challenges imposed by complex work content-for example, a high degree of manual work and human involvement-and identifies avenues for further research.

Bjørnbet and Vildåsen [23] present life cycle assessment as a tool for evaluating the environmental sustainability of circular business models. The authors draw on insights gained from a single longitudinal case study to highlight lessons learned regarding the interaction between life cycle assessment and circular economy and find that life cycle assessment offers a common platform for communicating with stakeholders.

Nåfors and Johansson [24] present the results of longitudinal research spanning eight years of industrial studies, where the researchers applied 3D laser scanning and immersive virtual reality to improve the layout planning processes of brownfield factories in real industrial scenarios, something the authors suggest is a novel approach in their research field. 
By using virtual engineering in such a fashion, industries can improve their brownfield factory layout planning process and make well-informed decisions, leading to sustainability benefits with fewer costly mistakes, improved employee engagement, and less need for travel.

Using a systematic literature review, Bertagnolli [25] complements existing research on lean manufacturing and sustainability by analyzing specific lean methods used in the context of sustainability and further exploring the sustainability characteristics of such lean applications. From an in-depth analysis of 81 case studies, the authors reveal the primacy of intra-company and ecological assessments in the lean context, while social and inter-company aspects also remain underexposed.

Im and Cho [26] explore the factors that influence the technological innovation efficiency of SMEs in South Korea. The authors use data envelopment analysis to identify specific criteria and provide a rationale to improve the efficiency of technological innovation in both the manufacturing and service industries.

Finally, Pawlik [27] examines the application of lean best practices in industrial remanufacturing processes. The authors identify specific lean methods that can help manage the inherent complexity of remanufacturing processes and consequently improve the overall productivity of these processes. This work also identifies factors that limit the application of lean practices within remanufacturing.

\section{Conclusions}

The nine works published in this Special Issue provide a broad overview of contemporary approaches to realizing more sustainable production systems and present specific examples and actionable knowledge that can be applied in other companies and settings around the world to advance the field and inspire fellow scholars in their current and future research on sustainable development within the limits of responsible production and consumption.

Specifically, the works of this Special Issue suggest that sustainable production cannot be reduced to a mere spontaneous action but rather is the result of a long-term strategic plan [20] based on circular business models centred on a new view of the economy [23]. Consistent with this theory, the implementation of any green strategy can only be achieved through a transformation process involving the continuous rethinking of organizational and managerial practices following the founding principles of lean thinking, as suggested by some of the articles presented herein, which address the role of lean concepts in achieving more sustainable production, such as the use of lean practices to resolve the challenges of remanufacturing [27] and to realize corporate sustainability [24]. In this new era of transformation, whether it is implemented in large companies or small- or medium-sized enterprises, technological innovation assumes a decisive and determining role [26], especially in the current situation influenced by the COVID-19 pandemic and characterized by the need to operate remotely to maintain safety while still improving operational efficiency [21]. By adopting specific smart tools and techniques [19], various technological advances leading to more sustainable production can then be implemented, such as the smart manufacturing execution system presented in [22] and the virtual engineering approach described in [23]. Nevertheless, regardless of which of these new or renewed manufacturing paradigms is implemented, some general advice emerges: The future appears bright and promising for those who are able to think lean and use technology to achieve the triple bottom line of sustainable production.

Author Contributions: Conceptualization, D.J.P., D.R. and P.G.; methodology, D.J.P., D.R. and P.G.; validation, D.J.P.; D.R. and P.G.; formal analysis, D.J.P., D.R. and P.G.; investigation, D.J.P.,D.R. and P.G.; resources, D.J.P., D.R. and P.G.; data curation, D.J.P., D.R. and P.G.; writing-original draft preparation, D.J.P., D.R. and P.G.; writing—review and editing, D.J.P., D.R. and P.G.; visualization, D.J.P., D.R. and P.G.; supervision, D.J.P., D.R. and P.G.; project administration, D.J.P., D.R. and P.G.; All authors have read and agreed to the published version of the manuscript. 
Funding: This research received no external funding.

Institutional Review Board Statement: Not applicable.

Informed Consent Statement: Not applicable.

Data Availability Statement: Not applicable.

Conflicts of Interest: The authors declare no conflict of interest.

\section{References}

1. Ohno, T. Toyota Production System: Beyond Large-Scale Production; CRC Press: Portland, OR, USA, 1988.

2. Womack, J.P.; Jones, D.T.; Roos, D. The Machine that Changed the World; Simon and Schuster: New York, NY, USA, 1990.

3. Johansson, G.; Winroth, M. Lean vs Green Manufacturing: Similarities and Differences. In Proceedings of the 16th International Annual EurOMA Conference: Implementation Realizing Operations Management Knowledge, Göteborg, Sweden, 14-17 June 2009; pp. 14-17.

4. Hallam, C.; Contreras, C. Integrating Lean and Green Management. Manag. Decis. 2016, 54, 2157-2187. [CrossRef]

5. Abreu, M.F.; Alves, A.C.; Moreira, F. Lean-Green Models for Eco-efficient and Sustainable Production. Energy 2017, 137, 846-853. [CrossRef]

6. Rashid, A.; Roci, M.; Asif, F.M.A. Circular Manufacturing Systems. In Handbook of the Circular Economy; Brandão, M., Lazarevic, D., Finnveden, G., Eds.; Edward Elgar Publishing: Cheltenham, UK, 2020. [CrossRef]

7. Rickert, J.; Blömeke, S.; Mennenga, M.; Cerdas, F.; Thiede, S.; Herrmann, C. Refining Circulation Factories: Classification Scheme and Supporting Product and Factory Features for Closed-Loop Production Integration. In Production at the Leading Edge of Technology, Lecture Notes in Production Engineering; Behrens, B.A., Brosius, A., Hintze, W., Ihlenfeldt, S., Wulfsberg, J.P., Eds.; Springer: Berlin/Heidelberg, Germany, 2021. [CrossRef]

8. O'Brien, C. Sustainable Production-A New Paradigm for a New Millennium. Int. J. Prod. Econ. 1999, 60-61, 1-7. [CrossRef]

9. The United States Environmental Protection Agency. Sustainable Manufacturing (Definition). Available online: https://www. epa.gov/sustainability / sustainable-manufacturing (accessed on 15 January 2021).

10. Ejsmont, K.; Gladysz, B.; Kluczek, A. Impact of Industry 4.0 on Sustainability-Bibliometric Literature Review. Sustainability 2020, 12, 5650. [CrossRef]

11. Choi, S.; Jun, C.; Zhao, W.B.; Do Noh, S. Digital Manufacturing in Smart Manufacturing Systems: Contribution, Barriers, and Future Directions. In Advances in Production Management Systems: Innovative Production Management towards Sustainable Growth; Umeda, S., Nakano, M., Mizuyama, H., Hibino, N., Kiritsis, D., Von Cieminski, G., Eds.; Springer: Berlin/Heidelberg, Germany, 2015; pp. 21-29. [CrossRef]

12. Qu, S.; Jian, R.; Chu, T.; Wang, J.; Tan, T. Computational Reasoning and Learning for Smart Manufacturing under Realistic Conditions. Intl. Conf. on Behavioral, Economic, and Socio-Cultural Computing; IEEE: New York, NY, USA, 2014. [CrossRef]

13. World Manufacturing Foundation. World Manufacturing Report: Digitally Enabled Circular Manufacturing. 2021. Available online: https:/ / worldmanufacturing.org/report/report-2021-digitally-enabled-circular-manufacturing/ (accessed on 15 January 2021).

14. Romero, D.; Gaiardelli, P.; Powell, D.; Wuest, T.; Thürer, M. Digital Lean Cyber-Physical Production Systems: The Emergence of Digital Lean Manufacturing and the Significance of Digital Waste. In Advances in Production Management Systems: Production Management for Data-Driven, Intelligent, Collaborative, and Sustainable Manufacturing; Moon, I., Ed.; Springer: Berlin/Heidelberg, Germany, 2018; pp. 11-20. [CrossRef]

15. Singh, S.; Ramakrishna, S.; Gupta, M.K. Towards Zero Waste Manufacturing: A Multidisciplinary Review. J. Clean. Prod. 2017, 168, 1230-1243. [CrossRef]

16. Powell, D.; Magnanini, M.C.; Colledani, M.; Myklebust, O. Advancing Zero-Defect Manufacturing: A state-of-the-art perspective and future research directions. Comput. Ind. 2022, 136, 103596. [CrossRef]

17. Romero, D.; Wuest, T.; Keepers, M.; Cavuoto, L.A.; Megahed, F.M. Smart Wearable and Collaborative Technologies for the Operator 4.0 in the Present and Post-COVID Digital Manufacturing Worlds. Smart Sustain. Manuf. Syst. 2021, 5, 148-166. [CrossRef]

18. Wuest, T.; Romero, D.; Khan, M.A.; Mittal, S. The Triple Bottom Line of Smart Manufacturing Technologies: An Economic, Environmental, and Social Perspective. In The Routledge Handbook of Smart Technologies: An Economic and Social Perspective; Kurz, H.D., Nunkoo, R., Eds.; Routledge: London, UK, 2020.

19. Lu, T. A Fuzzy Network DEA Approach to the Selection of Advanced Manufacturing Technology. Sustainability 2021, 13, 4236. [CrossRef]

20. Córdova-Aguirre, L.J.; Ramón-Jerónimo, J.M. Exploring the Inclusion of Sustainability into Strategy and Management Control Systems in Peruvian Manufacturing Enterprises. Sustainability 2021, 13, 5127. [CrossRef]

21. Subramaniam, R.; Singh, S.P.; Padmanabhan, P.; Gulyás, B.; Palakkeel, P.; Sreedharan, R. Positive and Negative Impacts of COVID-19 in Digital Transformation. Sustainability 2021, 13, 9470. [CrossRef]

22. Pfeifer, M.R. Development of a Smart Manufacturing Execution System Architecture for SMEs: A Czech Case Study. Sustainability 2021, 13, 10181. [CrossRef] 
23. Bjørnbet, M.M.; Vildåsen, S.S. Life Cycle Assessment to Ensure Sustainability of Circular Business Models in Manufacturing. Sustainability 2021, 13, 11014. [CrossRef]

24. Nåfors, D.; Johansson, B. Virtual Engineering Using Realistic Virtual Models in Brownfield Factory Layout Planning. Sustainability 2021, 13, 11102. [CrossRef]

25. Bertagnolli, F.; Herrmann, K.; Rittmann, I.; Viere, T. The Application of Lean Methods in Corporate Sustainability-A Systematic Literature Review. Sustainability 2021, 13, 12786. [CrossRef]

26. Im, C.H.; Cho, K.T. Comparing and Identifying Influential Factors of Technological Innovation Efficiency in Manufacturing and Service Industries Using DEA: A Study of SMEs in South Korea. Sustainability 2021, 13, 12945. [CrossRef]

27. Pawlik, E.; Ijomah, W.; Corney, J.; Powell, D. Exploring the Application of Lean Best Practices in Remanufacturing: Empirical Insights into the Benefits and Barriers. Sustainability 2022, 14, 149. [CrossRef] 